\title{
La contemplación en la acción de la justicia. La contribución de Ignacio Ellacuría a la espiritualidad cristiana
}

\author{
J. Matthew Ashley, \\ Universidad de Notre Dame, \\ Estados Unidos.
}

En este artículo quiero analizar la contribución de Ignacio Ellacuría a la espiritualidad cristiana. Ellacuría no escribió tan prolíficamente sobre la oración y la vida espiritual como, por ejemplo, Karl Rahner, y por ello su contribución a la espiritualidad pudiera no ser obvia a primera vista. De la lista de sus publicaciones, lo que normalmente llama la atención son sus aportes a la profunda fundamentación filosófica de la teología de la liberación, o su eclesiología "desde abajp". También llama la alención la profundidad de su hermeneútica, según la cual llamó a los pobres de América Latina el "pueblo crucificado", o sus análisis de la realidad nacional de El Salvador, articulados desde la perspectiva de ese mismo pueblo crucificado. Sin embargo, Ellacuría fue también un jesuila que conocía a fondo y personalmente la espiritualidad de su orden. Un breve vistazo a su biografía muestra que Ignacio Ellacuría fue un hombre apasionadamente comprometido con la espiritualidad ignaciana y que intentó ponerla al servicio de la Iglesia en América Latina'. En nuestra opinión, eso lo llevó a cabo, en gran parte, al buscar un lenguaje adecuado y argumentos filosóficos y teológicos para expresar el encuentro con Cristo, tal como ha quedado plasmado

1. Fue, por ejemplo, delegado de formación durantc cinco años (1969-1974), jaunque no sin controversias! Además, cuando los jesuitas centroamericanos tuvieron que elegir un delegado para la Congregación General XXXIII, en 1983, eligieron a Ellacuria, lo cual es, por lo menos, indicio de que vcian en Ellacuría a un jesuita con una apropiación personal y Jominio de la espiritualidad jesuita. 
en los Ejercicios espirimales de san Ignacio de Loyola. Y aunque lo que le hizo pensar fue la problemática especifica de la Iglesia latinoamericana, su pensamiento tiene mucho que aportar también al resto de la Iglesia. En nuestra opinión, Ignacio Ellacuría merece un lugar entre los teólogos jesuitas, tales como Karl Rahner, Henri de Lubac y Pierre Teilhard de Chardin, quienes trataron de elaborar los presupuestos e implicaciones conceptuales de la espiritualidad ignaciana para la modernidad tardia'.

A continuación vamos a intentar adentrarnos en lo que significaba para Ellacuría la espiritualidad ignaciana. Para ello tenemos los apuntes de las conferencias que dio en un curso sobre los Ejercicios espirituales.' Mucho se puede y se debe decir sobre su original interpretación de la obra maestra de san Ignacio, pero aquí me limitaré a analizar las implicaciones del uso del término filosófico "historización" - frecuente en los escrilos de Ellacuría- para identificar y poner a producir lo que para él era el dinamismo central de los Ejercicios espiriıualest. En una segunda parte mostraré el polencial de ese dinamismo, en el tratamiento de un tema específico e importante de la espiritualidad ignaciana, pero que va más allá de ella: la contemplación en la acción'. Para una espiritualidad que, en la modernidad encuentra su hogar en el mundo, esio ha sido, sin duda, un logro importante. Pero ofrece también dificultades, especialmente en nuestro entomo moderno actual, que privatiza la espiritualidad y la convierte en un conjunto de técnicas para hacer las paces con una cultura cada vez más alienada, en lugar de tratar de evangelizarla. En este contexto intentaré mostrar que la contribución de Ellacuría consiste, precisamente, en haber captado esa ambigüedad $y$ en haber proporcionado una respuesta crealiva, inspirada en el modo novedoso en que vivió e interpretó la espiritualidad ignaciana.

\section{Ellacuría y los Ejercicios espirituales}

No creo que sea una exageración decir que Ignacio Ellacuría fue un hombre obsesionado por el poder Iransformador de los Ejercicios espirituales de san

2. Para algunas reflexiones sobre csic tcma, véasc los cnsayos de Avery Dulles, "Saint Ignatius and the Jesuit Theological Tradition", Studies in the Sprituality of Jesuits 14 (1982); "Jcsuits and Thcology: Ycstcrday and Today". Theological Srudics 52 (1991), 524-538; "The Ignatian Charism and Contemporary Thcology", America 176 (1997), 14-22.

3. Véasc Ignacio Ellacuría, "Lcctura latinoamcricana de los Ejercicios espirisuales de san Ignacio", Revisia Latinoamericana de Teologia 23 (I99I) III-147; de aquí en adelante, "Lectura".

4. Para una discusión más detallada del compromiso intelcclual de Ellacuria con los Ejercicios espirituales, vćasc J. Matthew Ashlcy, "Ignacio Ellacuria and the Spiritual Exercises of Ignatius of Loyola", en Theological Studies 61 (2(K)) l6-39.

5. La claboración de csic tema por Ellacuría sc cncuentra en su cnsayo "Fe y justicia". que fuc publicado en dos partes en Chrissus 501 (1977) 26-33 y Chrisıs 50.3 (1977) 32-34. La quinta parte de este ensayo. titulada “La conlemplación en la acción de la 
Ignacio de Loyola. Juan Hernández Pico sugiere que la trayectoria de Ellacuría se puede resumir en su esfuerzo por actualizar (historizar, como diría el mismo Ellacuría) ese poder (ransformador en contextos sociales cada vez más amplios:

Lo que Ignacio Ellacuría hizo en su vida apostólica de jesuila, aunque no lo definió así programáticamente, fue hacer pasar por el espíritu de los Ejercicios espirituales primero y fundamentalmente a la Provincia Centroamericana, y especialmente a las estructuras de la formación de la juventud en ella, y luego a la Universidad Centroamericana "José Simeón Cañas" (UCA). Después, y desde ella, intentó hacer pasar por esa experiencia a la realidad nacional de El Salvador".

¿Qué tenian de especial los Ejercicios espirituales para él? Una comparación con su maestro teológico, Karl Rahner, puede proporcionar una respuesta. Rahner estaba convencido de que el horizonte de trabajo de todo jesuita, incluyendo su Irabajo intelectual, debía consistir en transmitir la experiencia de Dios, hecha posible y estruclurada por los Ejercicios espirituales?. Para el teólogo, esto exige encontrar un instrumental conceptual adecuado para comunicar y poder hacer uso de los recursos que ofrecen los Ejercicios. Especificamente, en su análisis de la experiencia de la consolación o de la desolación espirilual, tratada en los Ejercicios espirituales, Rahner afirmaba que, para el teólogo, lo más importante es si dispone ya en su teologia de los medios necesarios para hacerla realmente objeto de una conciencia refleja, para hacer más comprensible y para juslificar eso mismo que se vive en dichas obras, o si más bien no debe su leología comenzar por ampliarse a base de esas obras y sus enunciados, y dejarse corregir por ellas".

En ese mismo escrito, Rahner estaba especialmente interesado en las reglas ignacianas de discernimiento, especialmente en cuanto giran alrededor de la experiencia de la "consolación sin causa previa". Para Rahner, esta experiencia y estas reglas proporcionan a los cristianos una manera de encontrar a Dios y su voluntad en un mundo cada vez más secularizado y pluralista. Por consiguiente,

justicia", es de interés especial. Aqui usaré la versión reedilada de este ensayo: Ignacio Ellacuria, Jon Snbrino, Fe y justicia, Bilbao (1999). Otra fucntc importantc para su comprensión de la contemplación y la acción sc cncucnira en "Historicidad de la salvación crisliana”, en Ellacuria y Sobrino (eds.), Mysterium Liberationis: conceptos fundamentales de la tcologia de la liberación, San Salvador, 1991, I, pp. 323-372 (dc aqui cn adclantc citado como "Historicidad").

6. Juan Hernández Pico, "Ellacuría, ignaciano." en Jon Sobrino y Rolando Alvarido (cds.), Ignacio Ellacuria, "Aquella liberiad esclarecida", San Salvador, 1999, p. 305.

7. Vćasc Karl Rahner, "Palabras de Ignacio de Loyola a un jesuila de hoy", Santander 1990, pp. IIss.

8. Karl Rahner, "La Lógica del conocimiento exisıencial en San Ignacio de Loyola," en Lo dinámico en la lglesia, Barcelona, 1963, p. 119. 
su articulación teológica, su defensa y su elaboración, constituían para Rahner un servicio eclesial importante por parte del teólogo.

También para Ellacuría, la teología es servicio eclesial, y, como Rahner, el jesuila Ignacio Ellacuría acudió a los Ejercicios espirifuales para ofrecer ese servicio. Esta es la razón por la cual Ellacuría comienza sus conferencias sobre los Ejercicios sin mencionar el desarrollo espiritual del individuo, sino que comienza definiendo la necesidad más urgente de la Iglesia en América Latina: “El problema fundamental que enfrentan lanto la teología como la pastoral latinoamericana es el de comprender y realizar la historia de la salvación en la propia situación latinoamericana"wy. Esto fue, de hecho, el desafío que la Iglesia latinoamericana se había propuesto en Medellín: discernir los signos de los liempos a la luz del evangelio, en su propia realidad concreta y responder adecuadamente a ellos. Para Ellacuría, esta difícil tarea no se puede llevar a cabo aplicando, simplemente, normas universales establecidas en Roma, Europa o Norteamérica, ni haciendo uso, exclusivamente, de métodos socio-científicos. Aquello trivializa el problema y esto lo seculariza"'. La pregunta, entonces, es la siguiente: ¿dónde puede encontrar la Iglesia una posición esiratégica, un "lugar" desde el que se puede realizar esta tarea necesaria?

La respuesta es que los Ejercicios espirituales proporcionan ese lugar. Después de plantear el problema de cómo hacer para que la teología y la práctica pastoral sean latinoamericanas, Ellacuría titula la siguiente sección "Los Ejercicios de san Ignacio como lugar teológico de historización"". Ahora bien, "historizar", un concepto o un conjunto de conceplos (incluyendo conceptos teológicos tales como "la historia de la salvación" o "la voluntad de Dios"), significa (1) comprenderlo como parte de un proceso histórico en curso, (2) comprender cómo su uso se relaciona con, resiste o transforma los varios dinamismos que constituyen la siluación histórica específica de uno y (3) ser responsable ante el modo en que este entendimiento lo hace a uno actuar (o no acluar) en esa situación. El término se elabora en gran detalle en la filosofía de Ellacuría y su desarrollo muestra cómo se basó en su maestro filosófico Xavier Zubiri y lo sobrepasó'?. Presentar la historización como el pilar de la inlerpretación de los

9. "Lectura", p. 112. El título de esta sección del artículo es "Los Ejercicios como) experiencia tcologal y principio pastoral en la rcalidad eclesial latinoamericana". p. I II, énfasis añadido.

10. Ihid. 111 .

11. Ibid., p. It3. Este es cl lítulo de la scgunda parte (de dos) de su conferencia introductoria.

12. Tanto Kevin Burke, S. J., como Rohert Lassalle-Klein, sostienen que tanlo el término realidad histórica, como historización cstán prescnles en cl trabajo de Zubiri. pero que Ellacuría trans「ormó la filosofía de Zuhiri al hacer de cstos tćrminos los cjes sobre los que gira lodo el sistema. Véase Kevin Burke. The Ground Bencath the 
Ejercicios, significa que el término sirve para mostrar y poner a producir para la Iglesia lo que para Ellacuría era lo más importante de aquéllos Significa, además, que para comprender adecuadamente lo que para Ellacuría significa historización, hay que considerar no sólo su complicada base filosófica, sino también la concreción ejemplar de dicha historización en la importancia de los Ejercicios espirituales que, según san Ignacio, tienen para la lglesia. Comparándolo con Rahner, al desarrollar una filosofía y una teología basadas en la historización (y su correlativo importante, la realidad histórica), Ellacuría estaba forjando el insırumental conceptual para poner a disposición de la Iglesia en América Latina el potencial de una tradición espiritual.

¿Qué pretendía Ellacuría, realmente, al hablar de hislorización en el contexlo de los Ejercicios espirituales? Nos dice que los Ejercicios "historizan [la] palabra de Dios en cuanto recurren a signos históricos, personales y circunstanciales, para poderla descubrir concretamente"'? punto al afirmar que los Ejercicios "hacen de lo histórico la parte esencial de la estructura del encuentro cristiano de Dios"14. Para Ellacuría, esto aparece claramente en la "segunda semana", que "incluye los lextos más originales de san Ignacio"'s. La segunda semana es el punto en el cual el que se retira hace la "elección", una elección que determinará el curso de su vida (como, por ejemplo, el incorporarse a la vida religiosa). El hacer esta decisión en conformidad con la voluntad de Dios es el propósito de los Ejercicios. Con ese fin, la segunda semana ofrece un complejo entramado de contemplaciones de los misterios de la vida de Jesús. Estas contemplaciones, tomadas principalmente de los evangelios sinópticos, son un en Irentarse orante con la vida de Jesús, en que uno participa imaginativamente en el drama que relatan las historias para llegar a conocer y amar a Cristo, y, como consecuencia, imitarlo más de cerca. Estas contemplaciones se hacen en un trasfondo de reflexión melahistórica, tales como la comparación entre el llamamiento de Cristo y el llamamienlo de un rey terrenal, o de consideraciones discursivas y concepluales, como los diferentes grados de humildad e indiferencia a los que un cristiano es llamado, o las aplicaciones de diferentes "reglas de discernimiento". La finalidad es siempre hacerse cargo dc la propia historia de uno y hacer una decisión en conformidad con la voluntad salvadora de Dios, quien ha actuado y continuia actuando en la historia.

Al usar aquí el término "historización", Ellacuría está recalcando la manera en que los Ejercicios entretejen la historia personal e individual de la persona

Cross, 50-53, 123-130; Robert Lassalle-Klcin, "The Crilical and Creative Debl of Ignacio Ellacuria to Xavier Zuhiri", en The Love that Produces Itope (Liturgical Press, de próxima aparición).

13. Ibid., p. 113.

14. Ibid., p. 115.

15. Ibid., p. 124. 
con la historia mundial más amplia en que aquélla está enraizada, y finalmente, con la historia de la obra de salvación de Dios en el mundo, con su manifestación definitiva en la historia de Jesús. La meta, tal como la recalca Ellacuría, no es simplemente el conocimiento de Dios y de su voluntad, sino también la decisión de encarnar esa voluntad en la vida de cada uno's. La meta es la praxis del seguimiento de Jesús. Volviendo a la definición tripartita de historización que hemos presentado antes, a través de los Ejercicios, en primer lugar, la persona percibe la voluntad de Dios como parte de un proceso histórico, con su punto culminante en Jesús de Nazaret, pero que continúa en aquellos que Jesús envía por el mundo bajo su "bandera"'?. En segundo lugar, se esfuerza por comprender cómo esa voluntad especificada históricamente se aplica a la situación histórica propia. Por último, trabaja para desarrollar las disposiciones adecuadas y la apertura a la gracia, que hará que la persona actúe según el entendimiento que se ha adquirido de esta forma. El resultado es que se empieza a seguir a Jesús más de cerca. No se trata de imitar un ideal no histórico, sino de efectuar una continuación histórica. Ellacuría la llamó una "historización progresiva", guiada por "el espíritu de Cristo que anima a los que le siguen"'k. Estaba convencido de que los Ejercicios podrían conseguir esto no sólo para los individuos, sino también corporativamente, a condición, claro está, de poder formular estructuras filosóficas y teológicas adecuadas para desencadenar su fuerza ${ }^{14}$. La conclusión es que los Ejercicios espirituales fueron tan importantes para Ellacuría no sólo por ser jesuita, sino también porque le proporcionaron un instrumento esencial para responder a las necesidades de la Iglesia católica de América Latina.

Ellacuria no ha sido, ciertamente, el único en captar el énfasis ignaciano en lo histórico como lugar para la oración y la acción. El historiador del misticis-

16. /hid., pp. 113-114.

17. Véase "El Ilamamiento del rey temporal y del rey eternal," Ejercicioss espirituales, nos. 9l-100, y "La meditación de dos bandcras," nos. 136-148, cn Ignacio Iparraguirre (ed.), Obras completas de San Ignacio de Loyola, Madrid, 1952, pp. $178-180,186-188$.

18. "Lecturi", p. 127.

19. Pienso que Ellacuría lo aprendió durante sus años de noviciado bajo el extranrdinario Miguel Elizondo, y que lo intentó poner en práctica por primera vez al dar corporativamentc los Ejercicios espirituales a los jesuitas centroamericanos, en 1969. Sobre su noviciado y el papel imporlante que Elizondo dio a los Ejercicios para inculturar a sus novicios, véase Terewa Whilfield, Paying the Price: Ignacio Ellacuria and the Murdered Jesuits of El Salvador, Philadclphia, 1995, pp. 15-24. Sobre cl retiro a toda la provincia, véase Juan Hemández Picn, "Ellacuria, ignaciano," pp. 305-326; Robert Lassalle-Klein, The Jesuit Martyrs of the University of Central America: An American Christian University and the Historical Reality of the Reign of Gord (Tesis doctoral, Graduate Theological Union, 1995), pp. 51-56, y Charles Beirne. S.J.. Jesuil Education and Social Change in El Salvador. New York, 1996, pp. 84-87. 
mo, Ewerl Cousins, pone a san Ignacio en la tradición que llama "el misticismo del acontecimiento hisı́rico", que se remonta, por lo menos, a san Francisco de Asís ${ }^{21}$. Lo que unifica a toda esa tradición, según Cousins. es una devoción a la humanidad de Cristo, ejemplificada en la construcción de un pesebre para la misa de Nochebuena, en Greccio, en 1223. Este modo de enfocar la encarnación de Jesús dio origen a una tradición que ofrece una verdadera alternativa a la tradición mística neoplatónica con su inclinación hacia el Cristo resucitado y glorificado, y su tendencia a encontrar en los acontecimienlos históricos sólo alegorías que impulsan al mislico a ir -más allá de la historia- hacia lo eterno"'. Cousins describe esta alternativa de la siguiente manera:

Creo que [esta nueva [orma de oración] está enraizada en la historicidad misma de la exislencia humana y que activa esa dimensión de la psique por medio de la cual extracmos energía espiritual de un acontecimiento del pasado. En otro lugar he llamado a esto "misticismo del acontecimiento histórico". Con eso quiero decir que constituye una característica bien diferenciada de la conciencia mística. Así como en el misticismo de la naturalcza nos sentimos unidos al mundo material, así lambién en esta forma de mislicismo nos sentimos parte del acontecimiento histórico —como si allí estuviéramos como testigos, participando en la acción. absorbiendo su energía?2.

Cousins continúa analizando el trabajo de la teología franciscana -encabezada por Buenaventura-, que integra esta nueva espiritualidad en las tradiciones teológicas clásicas cristianas, que se habian desarrollado principalmente en la corriente neoplatónica". Esta integración no sólo ofreció una articulación conceptual a la espiritualidad de san Francisco, sino que también llevó a cabo un cambio fundamental al "franciscanizar" los fundamentos de la estructura reológica neoplatónica. Cousins termina preguntándose si san Ignacio ha tenido también su "Buenaventura" para integrar su visión espiritual en la corriente más amplia de la espiritualidad cristiana y para situarla dentro de una visión teológica comprehensiva ${ }^{24}$.

20. Los textos pertinentes son Ewert Cousins, "Franciscan Roots of Ignatian Medilation". en Ignatian Spirituality in a Secular Age, Gcorge Schner, S. J. (ed.), Waterlon, 1984, pp. 51-64; "The Humanity and Passion of Christ," en Christian Spirituality II: High Middle Ages and Reformation. Jill Railt (ed.), New York, 1989, pp. 375-391: "Francis of Assisi: Christian Mysticism at thc Crossroads," en Mysticism and Religious Traditions, Steven Kalz (ed.), New York, 1983, pp. 163-191.

21. Véase "The Humanity and Passion of Christ", pp. 376-380.

22. "Franciscan Rools of Ignatian Meditatio", p. 60.

23. "Francis of Assisi", p. 175.

24. "Franciscan Roots", p. 63. El autor sugiere que Buenaventura podria, todavía hoy. rcalizar esa tarea en relación a san lgnacio, o un tcológo contcmporánco fucrtementc influido por Buenaventura: Karl Rahner. 
De hecho, lo esencial de lo que hemos dicho hasta ahora consiste en proponer a Ellacuría como principal candidato para esa tarea. Aunque nunca usó estos términos, Ellacuría comprendió muy bien "el misticismo del acontecimiento histórico", que está en el centro de esta espiritualidad ignaciana, y se esforzó por elaborar una filosofía que pudiera poner de relieve esa espiritualidad y desplegar su potencial. Para ello eligió el instrumental de Zubiri, pero también de Marx y de otros. "ignacianizándolos". De esta manera, su obra filosófica no sólo esclarece su comprensión de la espiritualidad ignaciana, sino que, lambién a la inversa, su comprensión de la espiritualidad ignaciana ayuda a comprender su agenda filosóficas. La profundidad de la apropiación de esta estruclura básica de la espiritualidad ignaciana y de su influjo se pone de manifiesto al considerar cómo comprende Ellacuría el tema intrínsecamente ignaciano de "la contemplación en la acción".

\section{2. "La contemplación en la acción de la justicia": la contribución de Ellacuría a la historia de un concepto}

Libros enteros se han escrito sobre la historia de la relación "contemplación y acción", y no es mi intención hacer un resumen de esla historia. Lo que quicro mostrar es que el modo que tenía Ellacuria de comprender el tema conlemplación y acción se relaciona dialécticamente con los temas centrales de su tcología $^{20}$. El tema es importante. y para comprender lo que está en juego teológicamente en una determinada comprensión de la relación entre oración y acción, presentaré algunos autores de la tradición”- En sus origenes. la reflexión crisiliana sobre el lema quedó determinada lerminológicamente por la incorporación que hizo la patrística del debale griego sobre la relación entre leoría y praxis, $y$. desde la perspecliva de la Escrilura, por las parejas biblicas de Lía y Raqucl, Pedro y Juan, Marla y María. Origenes fuc, probablemente, el primero en asociar a Marta con una vida de praxis y a María con unil vida de theoria. Al hacerlo, acepló en gran parte la valoración superior de la theoria en los filosófos de la antigüedad, asi como los argumentos que emplearon para establecer dicha

25. Para una profundización en el tema, vèse Ashley, "Ignacio Ellacuria and the Spritual Excrciscs", 30-37.

26. Ellacuria es un claro ejemplo de un pensador moderno crisliano que superó la lípicil dicolomía moderna entre espiritualidad y leologia, la cual ha sido criticada por pensadores lan diversos como Hans Urs von Ballhasar. Divid Tracy y Guslavo Gutièrrez.

27. Para una historia más completa del tema hasta finales de la edad media, véase Dictmar Micth. Dic Einheit von Vita activa und Vita comf'mplativa in den deutschen Predigten and Trakiaten Meister Eckharss und bei Johamies Tauler (Regenshurg. 1969). Para una historia de lis rellexicin subre Marla y Maria a través de la reforma. véusc Giles Constable. "The Interpretaltion of Martha and Mary", en Threse Srudics in Medieval Religious and Social Though, Cambridge (I0)S) $1-14 \mid$. 
superioridad ${ }^{2 k}$. Estos argumentos generalmente se basaban, en la anligüedad tardía, en un esquema neoplatónico, según el cual la participación en lo temporal, en general, y en la vida política, en particular, era descrita en forma cada vez más negativa. Dos de esıos argumentos son importantes para nuestra reflexión. El primero es que la praxis -que para los antiguos significaba ante todo la vida política- compromete a la persona en los asuntos temporales, lo que dispersa sus energías; mientras que la theoria, como contemplación de lo que es eterno. la aleja de la dispersión de la existencia temporal. Preferir theoria a praxis es preferir la unidad a la pluralidad. El segundo es que la realización plena de la praxis, ubicada en la polis, queda al capricho de las circunstancias históricas y de la cooperación de otros seres humanos; mientras que la theoria no depende del entorno social. Se puede llevar a cabo en aislamiento o en el contexto modesto, pero más estructurado, de la escuela filosófica. La theoria es más autosuficiente. Preferir theoria a praxis expresa, entonces, realismo en los ideales que se escogen para estructurar la propia vida. A medida que la polis fue degenerando en la anligüedad tardía, tanto en sus formas griegas como romanas, este realismo se expresó cada vez más en el rechazo de la praxis como lugar posible para la realización humana ${ }^{20}$.

Con la adopción de estas calegorías por los apologetas cristianos, lodo el milenio posterior puede ser considerado como una larga tarea para superar las limilaciones filosóficas de las calegorias griegas, de modo que pudiesen expresar adecuadamente la complejidad de la vida del seguimiento de Jesús, tal como que se describe en el Nuevo Testamento. San Agustín de Hipona es figura importante, porque fue en buena parte responsable de transmitir este debate a la cristiandad latina, y porque desarrolló estrategjas teológicas que resultiron cruciales para reconfigurar la lógica de pruxis y theoria. Una de sus contribuciones imperecederas fue el haber explicitado el necesario cambio en el conlexio social: de la polis a la ecclesia, de la ciudad de los hombres a la ciudad de Dios. También capló la necesidad de una relerencia cristológica para poner en relación praxis y theoria, acción y contemplación"'. Finalmenle, san Agustín abordó el tema de cómo valorar la temporalidad, lo cual se convirlió en trans[ondo crucial para la valoración de los dos lipos de vida. Examinémoslo más en delalle, comenzando con la segunda.

En sus homilías sobre Lucas 10, 38-42, san Agustín propone el contexto unificador para comprender a Marla y María en su relación con Jesús. Marta dio de comer al Jesús encarnado, mientras que Maria se alimentó de Jesús en el

28. Para una visión general de estos argumentos, véase Nicholas Lobkowicz. Theory and Practice: History of a Concept from Aristolle io Marx, New York, 1967, pp. 3-57.

29. Véasc Lobkowicz, Theory and Practice, 53-57.

30. Sobre la comprensión de san Agustín de la relación entre la vida activa y la vida contemplativa, véase Mielh, Einheit, 84-96. 
espíritu". En la historia continuamos dando de comer al Cristo encarnado en los necesitados (san Agustín cita a Mt 25); y Cristo, la palabra de Dios, nos da de comer, principalmente en la liturgia. Esto abre el camino para comprender la unidad de los dos tipos de vida con el apoyo de la lógica calcedoniana, que se aplica a las dos naturalezas en la unión hipostática — sin confusión, sin cambio, sin división, sin separación. San Agustín da forma más clara a este enfoque cristológico desde una explicación escatológica: "El tipo (de vida) que Marta llevaba, alli es donde estamos; el tipo de vida que Maria llevaba, ésa es la que anhelamos. Vivamos bien esta vida para disfrutar la olra al máximo":-2. La vida de Marta, de servicio a las necesidades de otros, es plenamente posible y obligatoria para nosotros ahora. La vida de María, absorta en la palabra, no es plenamente posible ahora; está presente sólo de manera incipiente, particularmente, sugiere san Agustin, en la liturgia ${ }^{3 .}$. Según esto, san Agustin interpreta asi el reproche de Jesús a Marta en Lucas 10,41s:

Así al Señor no le pareció mal el trabajo, pero hizo una distinción entre los deberes. "Tú estás ocupada —dijo- con muchas cosas; pero, de verdad, sólo una cosa es necesaria. María ya ha escogido eso para sí misma; la multiplicidad de trabajos pasa, y la unidad singular de la caridad permanece. Así no le quitarán lo que ella ha escogido. Sin embargo... te quitarán a ti lo que has escogido. Pero te lo quitarán para beneficio luyo, para que recibas la mejor parte":34.

San Agustín hizo uso de la lógica de que la theoria está por encima de la praxis, y a su vez la transformó. Acepló la prioridad neoplatónica del Uno sobre lo múltiple, el enfoque integrador de la contemplación sobre la exterioridad disipadora del servicio. Por otra parte, llevado de la prudencia, rechazó que se eligiese la theoria como el mejor candidato para una vida humana plenamente realizada. Las exigencias de la caridad prohiben tal elección y la naluraleza efímera de la unión contemplativa en esta vida invalida la lógica subyacente. Ahora podemos desear más la vida contemplativa, pero debemos vivir sabiendo que será lograda solamenle más allá de esta vida, y sabiendo que ahora hay que vivir dando prioridad a la vida del servicio caritalivo, que representa la praxis, disfrutando a lo largo del camino de aquellos breves anticipos que están a nuestra disposición - por fugaces que sean- en la vida de la theoria.

Estas ideas fueron expresadas en perspectiva eclesiológica en La ciudad de Dios, donde san Agustín habla de la vida mixta (vita mixta)". La vita activa y

31. San Aguslin, Sermón 103.J, en The Works of Saint Augustine: A Translation for the 2/st Century, New York, 1990, Vol. III, partc 5: pp. 76s. Cfr. Scrmón 104.3, cn Works, p. 82.

32. Sermón 104.4, en Works, 83s.

33. Ibid., p. 84.

34. Sermón 104.3, p. 83.

35. Libro XIX. 19, en The Ciry of God, Marcus Dods (Irad.), con una inlroducción de Thomas Mcrion. New York, 1950, pp. 697s. 
contemplativa se coordinan desde la perspectiva del amor. La vita activa responde a la necessitas caritatis - la necesidad del amor de responder a las necesidades de otros. La vida contemplativa es asociada a la suavitas ex caritate - la paz y la tranquilidad del amor de Dios. Aparece de nuevo la perspectiva escatológica que anteriormente mencionamos. En efecto, mientras que inicialmente la vita activa y la vita contemplativa eran presentadas la una junto a la otra, es claro por el contexto que la vida mixta representa la única forma en que las otras dos son posibles en una Iglesia in statu viae. Es el único camino abierto a los cristianos de seguir a Cristo ${ }^{\text {in }}$ bajo las condiciones escatológicas de nuestro estado aclual.

La contribución de san Agustín a la comprensión de la vida contemplativa y la vida activa consiste, pues y ante todo, en establecer nuestra relación con Cristo, que se expresa en términos del amor - la norma por la cual ambas vidas son juzgadas e intertelacionadas-, lo cual ofrece una modificación importante del modelo griego de praxis y theoria. En segundo lugar, san Agustín comprendió las dos vidas en el contexto de la Iglesia y la ciudad de Dios. Finalmente, como san Agustín desarrolla su eclesiología de forma escatológica, descarta que hay que hacer una simple elección de una vida sobre otra. Sin embargo, por mucho que san Agustín muestre la necesidad de la vida acliva, a fin de cuentas, la acción está relacionada sólo extrínsecamente con la unión con Dios, que es nuestra finalidad, ya que esa unión se define en términos de la visión contemplativa, que será perfecta en la próxima vida, mientras que en ésta sólo es disponible en forma incoativa y efimera.

La importancia de Meister Eckhart para nuestro estudio se ve inmediatamente al leer sus extraordinarios sermones sobre Marta y María. En ellos Marta, y no María, es la cristiana madura, la que ha llegado al final del itinerario místico, en cuanto esto es posible en esta vida." En el Sermón 2, que, significativamente, sólo trata de Marta, Eckhart nos dice que Marta es "virgen y esposa".".k. Es un alma virgen "libre de toda imagen extraña". Es un alma esposa en la medida en que da fruto; en ella, Dios es fructífero. ${ }^{14}$. Sorprendentemente, Eckhart sostiene que "esposa" —que aquí connota la vida activa—, es un título más noble para el

36. Véase la discusión de Mieth. Einheir, 93-95.

37. Véasc Scrmón 2, en Meister Eckhart: the Essential Sermons, Commentaries, Trearises and Defenses, traducciones c introduccioncs de Edmund Collegc y Bernard McGinn, New York, 1981, pp. 177-181; y Sermón 86, en Meisfer Eckhart:Teacher and Preacher, editado por Bcrnard McGinn, New York, 1986, pp. 338-345.

38. Scrmón 2, Meister Eckhart: the Essential Sermons, p. 177. ¿Eckharl se toma libertades al traducir del latin a la lengua vernacula. Traduce mulier en Lucas 10, 38 por virgen y esposa!

39. Ibid., p. 178. Invirticndo la tendencia de la tradición, afirma que aquí “"csposa' cs la palabra más noble que se puede aplicar al alma, mucho más noble que 'virgen”" 
alma que el de "virgen", porque implica el ser fructífero". Lo mejor es el alma que es una virgen que es una esposa. Combina el desprendimiento de la virgen con el ser fructífero de la esposa:

Esta virgen, que es una esposa, produce este fruto y este nacimiento, y cada día produce fruto, cien o mil veces, sí, más de lo que se puede contar, dando a luz y haciéndose fructífera desde el fundamento más noble de todos $\longrightarrow$, para mejor decirlo, desde el fundamento desde el que el Padre está dando frulo a su Palabra eterna, desde ese mismo fundamento clla está dando a luz frucliferamente con él. Pues Jesús, la luz y la reflexión del corazón del Padre... ese Jesús está unido con ella y ella con él, y ella brilla y resplandece con él como uno en la unidad y como una luz pura y brillante en el corazón del Padre ${ }^{4 !}$.

Cuando una persona está enraizada en este "fundamento", entonces goza de una unión con Dios tan profunda como la unión que es la meta de la contemplación, de la theoria. "Aquí una obra que se hace en el tiempo es tan valiosa como cualquier unión del ser con Dios, ya que esta obra nos une tan estrechamente como lo más sublime que nos puede suceder, con la excepción de ver a Dios en su naturaleza pura"dz. Dejando de lado el ver a Dios en su naturaleza pura - Io cual se reservaba generalmente para la otra vida - si es que era considerado como posible en absoluto, Eckart opera una extraordinaria inversión de la tradición al afirmar que la acción, cuando es fruto de un alma apropiadamente dispuesta, nos une lan plenamente a Dios como cualquier cosa que pueda sucedernos en esta vida, incluyendo (el contexto lo hace patente) el éxtasis contemplativo, representado por María. Y lo que es más, como esta "acción enraizada en el fundamento" puede ser mantenida duraderamente (mientras que Eckhart seguía la tradición de que el rapto místico no podía serlo), es superior a la contemplación. El tipo de unión con Dios que acaece en la "acción fundamentada", representada por Marta, puede ser mantenida continuamente. Por esta razón es superior a la unión que ocurre en la oración contemplativa, particularmente para las personas fuera del monasterio. Por ende, Eckhart hace que María sea la principiante, y Marta la experta; la mejor parte que María ha escogido es, de hecho, la parte de Marta ${ }^{43}$. Eckhart interpreta la protesta de Marta como expresión de su

40. Este tema ya habia sido esbozado en la (radición, especialmente cuando se hizo uso de la parcja Lía y Raqucl para iluminar la rclación. En csta parcja, Lia es fructífcra, pero "con la vista entristecida". mientras que Raquel (al principio) no da fruto, pero sí es bella con la visla despejada. El ser fructifero del amor fue central en el llamado misticismo nupcial, y cs muy posible que Eckhart lo haya tomado de los místicos begüinos como Hadewijch y Mechthild de Magdehurgo, quienes representan un punto culminante en el desarrollo del tema.

41. Scrmón 2, Meister Eckhart: the Essential Sermons, p. 179.

42. Sermón 86, Meister Eckhort: Preacher and Teacher, p. 341 s. En「asis añadido.

43. "Marta conocia mejor a María que Maria a Marta, ya que Marta había vivido mucho y bicn; y cl vivir da cl tipo de conocimicnto más valioso" (Scrmón 86. p. 338). Por lo 
preocupación de que María se ha quedado tan absorta en el gozo de la contemplación que no lo abandonará por la unión más profunda de la persona, cuya alma es "virgen y esposa" + .

Eckhart usó una complicada metafísica leológica para fundamentar su propuesta de que la participación en la vida de Dios (theiosis), que es nuestra salvación, puede ser comprendida no sólo en términos de la unión del conocedor y lo conocido en la visión especulaliva —que era la meláfora dominante, asumida con el concepto griego de theoria y que subyace a la noción escolástica de la visión beatífica-, sino en lérminos de una unión en y con la acción divina que es Dios. Para Eckhart, Dios se caracleriza por el "bullir" (bullitio) intratrinitario del engendramiento elerno del Hijo por el Padre, en la unión del Espíritu. Esta vida trinitaria se "desborda" (ebullitio), en el acto elemo de la creación y en el aclo hislórico de la encarnación, donde el acontecimiento del engendramiento trinitario interior sella la creación. Para Eckhart este acontecimiento trinitario interior puede ser recapitulado conscientemente dentro del alma que es virgen y esposa cuando la persona "penetra" en su fundamento en Dios, un fundamento en el que Dios y el alma son unots. La acción se convierte ella misma en lugar para un tipo de unión con Dios que no es meramente preparación para una unión con Dios, en la visión contemplativa, ni fruto (por necesario que sea) subsecuente. Este tipo de unión no es tanto una "experiencia" que hacemos, sino un modo de ser en el que participamos. Como afirma Dietmar Mieth, "para Eckhart, la unio mystica del nacimiento de Dios consiste no en una experiencia, sino más bien en la integración ontológica de la persona en la obra divina de la salvación, la cual procede de Dios y regresa a Dios"

La contribución de Eckhart, por lo tanto, es la de superar, o, por to menos, complementar la imagineria "ocular" que dominaba la comprensión de la unión mística, y que hacía que fuera tan difícil concebir la acción como un lugar donde pudiera acaecer la unión mística. El cristianismo moderno es heredero de

tanto, Eckhart inviertc otra valoración, scgún la cual cl contcmplativo conoce mcjor al activo porque la vida activa es un preludio de la contemplativa.

44. Ibid., pp. 339, 343s. En cscncia, Jesús le dice a Marta que lo deje a él prencuparsc por Maria, que a clla, en cfecto, no sc le ncgará la mejor parte (la vida de Marta) quc ella ha escogido, aunque actualmenle Maria sólo está en las primeras etapas del camino que conduce a la vida de Marla: "El respondió al darle a clla [a Marta] cl mensaje reconfortante que todo saldria para Maria tal y como lo descaba" (p. 339).

45. Para una perspectiva general de este lema, que también argumenta de manera persuasiva en pro de la importancia de tcmas cxplícitamente tcológicos en la visión mistica de Eckhart, vćase Bcrnard McGinn, "The God Bcyond God; Theology and Mysticism in the Thought of Meister Eckhart", Journal of Religion 61 (198I), 1-19. Sobrc la tcologia trinitaria de Eckhart en particular (y las idcas de bullitio y ebullitio), véasc pp. 12-15.

46. Mielh, Einheit, p. 215. 
este concepto de "misticismo de la vida cotidiana". Hay que reafirmarlo en la medida en que ha derribado una división elitista del trabajo en la Iglesia, según la cual la oración, en particular la oración mística, ha sido reservada a aquellos que "dejan el mundo" por la vida monástica o eremítica, mientras que los laicos y aun los sacerdoles y religiosos fuera del monasterio se quedan con el trabajo de la evangelización y el servicio cristiano - areas encomiables, pero que necesariamente excluyen la vida de retiro silencioso, que requiere la oración contemplativa. Sin embargo, la visión de Eckhart ofrece también su lado oscuro, que ha surgido del panorama cultural de las sociedades modernas capitalistas tardias. Como advierte el sociólogo de la religión Robert Wuthnow, de la Universidad de Princeton, en Estados Unidos la espiritualidad no es que haya sido integrada en la vida cotidiana, sino que, más bien, ha sido absorbida por ella. La espiritualidad está en peligro de convertirse en un paliativo, un nuevo santuario en un mundo desalmado ${ }^{47}$. En este contexto, apelar a "la contemplación en la acción" amenaza con convertirse en un halo con el que envolvemos cualquier actividad para convencernos de que no hemos perdido nuestro rumbo -en particular, nuestro rumbo a lo sagrado- en el laberinto moderno tardío que hemos construido.

Además, la espiritualidad se ha convertido en un producto rentable. "La espirilualidad se ha convertido en un gran negocio", sugiere Wuthnow, "y el gran negocio encuentra los mejores mercados empacando las cosas en paquetes pequeños que son fáciles de consumir"4n. "La contemplación en la acción", es cierlamente, un producto muy vendible, ya que puede ser lanzado al mercado a cualquier persona, en cualquier ocupación, que se sienta abrumada o alienada por su trabajo. Sin embargo, en el proceso de simplificar y de vender la mercancía se pierden matices importantes y se eluden cuestiones crílicas. ¿Puede cualquier acción ser la base de la "contemplación en la acción”? ¿Se puede abstraer la sabiduría que existe en esta Iradición y en las prácticas que propicia, e insertarlas después en cualquier contexto instilucional de acción? Hay un nuevo género de literatura - en aumento- que saquea las tradiciones místicas y da un sí implícito a estas preguntas. Por ejemplo, en la floreciente literatura de "la espirilualidad de los negocios", las prácticas místicas se ofrecen como técnicas ideales por medio de las cuales los ejeculivos pueden manejar el estrés, aumentar el espíritu de compañerismo empresarial y obtener un mayor sentido de satisfacción respeclo de su Irabajo, sin considerar jamás el impacto social más amplio de las

47. Wuthnow afirma lo siguicnte sobrc la cspiritualidad en Estados Unidos: "Nucsira espiritualidad es a menudo poco más que un recurso terapéutico. Una relación con Dios es una forma de hacernos sentir mejor... Rezamos por el consuelo que nos produce, pero no esperamos ser desafiados. Hemos domesticado lo sagrado al quitarle su sabiduría autorizada y al mirarlo sólo para sentirnos felices". Véase Robert Wuthnow, God and Mammon in America. New York. 1994, pp. 5s.

48. Wuthnow, After Heaven: Spirituality in Americe since the 1950s, Berkelcy, 1998, p. p. 132. 
prácticas de la empresa ${ }^{14}$. ¿Tiene razón Wuthnow cuando muestra su prcocupalción porque las tradiciones espirituales del cristianismo están siendo "empaquetadas", aun por profesores bien intencionados y directores espirituales, como poco más que técnicas que nos ayudan a acomodarnos y adaptarnos a nuestro mundo cada vez más fugaz y complejo? ¿Puede ser reconfigurado el idcal de la contemplación en la acción para que tenga un lugar más central en el desafio profético de este mundo, en solidaridad con sus viclimas?

En esta reconfiguración consiste precisamente la contribución de Ignacio Ellacuría. Su propuesta es unir contemplación y acción, pero de modo que sca "una contemplación en la acción de la justicia". Al hacer eslo. Ellacuría rełomó no sólo los elementos de la espirilualidad de san Ignacio de Loyola, que tsiaban en continuidad con Eckhart, sino que apuntó a la esıructura básica histórica de la espiritualidad ignaciana, comprendida por él en términos de "historizición", como ya hemos visto. Al hacerlo, integró elementos importantes de la síntesis agustiniana, traspuestos por una profunda sensibilidad moderna a la historicidad humana. Voy a retomar, primero, la continuidad con Eckhart, y luego la configuración cristológica y eclesiológica de la síntesis de Ellacuría. que superan algunas de las debilidades, particularmente en el terreno moderno tardio, del modelo de "la contemplación en la acción".

Por lo que toca a lo primero. Ellacuría se apropia de la idea de tckhart de que la unio mystica no debe ser concebida exclusivamente en términos de visión, sino que puede ser comprendida como un "actuar con", to que recapitula tanto la generación eterna de la Palabra dentro de la Trinidad, como la creación temporal y la redención del mundo ad extra. Considérese, por ejemplo, el tratamiento que da Ellacuría a la máxima de san Ignacio de "encontrar a Dios en todas las cosas" y la noción de la contemplación en la acción implícita en ella. Aunque la frase no se encuentra allí, el lugar tradicional para discutirla ha sido la "contemplación para alcanzar amor", que pone fin a los Ejercicios espiritua. les de san Ignacio". Tal como la presenta Ellacuría, esta contemplación "muestra, desde el punto de vista de la fe, la posibilidad real del encuentro de Dios en la creación y la posibilidad de recuperación de la creación como presencia de Dios":!. Y añade que "se trata de una contemplación de Dios en las cosas, que va a dar paso a la contemplación en la acción con las cosas", en la cual "Dios se hace presente al hombre haciendo y el hombre hace presente a Dios y se hace presente a Dios haciendo"s2. El punto crucial que hay que recalcar de este comentario es que estos tres acontecimientos o procesos - Dios haciéndose pre-

49. Véase, por cjemplo, Gay Hendricks y Kate Ludeman, The Corporosc Mystic, New York, 1997.

50. Ejercicios espirituales, nos. 234-237 (204-206).

51. "Lcctura", p. 143.

52. Ihid., p. 146. 
sente, la persona haciendo que Dios esté presente y la persona haciéndose presente a Dios haciendo- son estrictamente correlativos y simultáneos. Encontramos a Dios en todas las cosas al trabajar en medio de lodas las cosas.

Así como en sus obras latinas Eckart hizo uso de todas la complejidad y matices del método escolástico para apoyar las ideas sobre la contemplación en la acción que exponía en sus sermones en lengua vernácula, así Ellacuría, como ya hemos visto, se esforzó por elaborar una estruclura filosófica que mostrara e hiciese uso de las ideas que intuyó en su interacción con la espiritualidad ignaciana. Otra semejanza entre los dos es el remontarse a la ontologia trinitaria. Esto es particularmente evidente en el artículo de Ellacuría sobre "La historicidad de la salvación cristiana". Allí, a medida que diseña el camino hacia su afirmación del ideal de la conlemplación en la acción al linal del artículo, insiste en que la creación debe ser comprendida como "la plasmación ad extra de la propia vida trinitaria, una plasmación libremente querida, pero de la propia vida trinitaria".s" Esta presencia continua y constitutiva del Dios trinitario respecto de la creación es lo que Ellacuría tiene en mente cuando habla de "la dimensión teologal" de la realidad ${ }^{\text {s. }}$. Esta dimensión da lugar a un carácter profundamente dinámico y aulodonador en la realidad. Se hace más plenamente presente y aclualizado en la praxis humana y la historia que constiluye. Asi como para Eckhart el trabajo puede ser una participación en la obra crealiva de Dios, para Ellacuría la praxis es una participación en la presencia creadora y transformadora de Dios en la raíz misma de la realidad, lo cual es, a su vez, la forma más adecuada de la "vía unitiva" hacia la intimidad con Dios.

De este modo, las "cosas" en las cuales encontramos a Dios no están solamente "ahí afuera", estáticamente, para la observación y la manipulación pasivas. Un conocimiento adecuado de las cosas como elementos de la realidad histórica debe ir más allá de una observación y descripción de las realidades desde afuera. Por el contrario, tal conocimiento debe incluir "un estar 'real' en la realidad de las cosas, que en su carácter activo de estar siendo es todo lo contrario de un estar cósico e inerte" $"$. A nivel teologal, significa hacerse presente

53. "Historicidad", Mysterium Liberationis, p. 357.

54. "Historicidad", p. 358. Ellacuría alribuyc csta idca filosófica a Zubiri. Cabc notur. sin embargo, que también corresponde al carácter profundamente trinitario de la espiritualidad ignaciana. Esta centralidad ya habia sido presentada convincentemente por Pcdro Arrupc (a quicn Ellicuria respetaba inmensamentc) como la "hisiorización" de la espiritualidad ignaciana para nuestros tiempos. Lo hizo en un discurso que luvo cualro años antes de la puhlicacion Jel articulo de Ellacuria sobre la hisloricidad (Pedro Arrupc, "The Trinilarian Inspiration of the Ignatian Charism". 1980). Aqui encontramos otro provocador lejido entrecruzado de la espiritualidad (ignaciana, como la interpretó Amupe), la filosofía (de Zuhiri) y la teologia (de Ellacuria).

55. Véase cl cshozo de Ellacuría de una fundamentación filosófica de la lcología de la liberación, en "Hacia una fundamentación del método leológico latinoamericano," 
ante un Dios trinitario que está obrando en las cosas, como san Ignacio lo expresa tan claramente en "la contemplación para alcanzar amor"s $"$. El "eslar 'real' en la realidad de las cosas" es encontrarse de la manera más profundamente posible con un Dios trinitario que está obrando por nosotros precisamente al colocarsc uno junto con esa obra y en ella.

El acudir a ese fondo teológico-filosófico, lan necesario para la reconfiguración del modelo de la contemplación en la acción, exigió de Ellacuría su profunda resistencia, sostenida e implacable, a la depreciación de la historia y de la temporalidad. Esla depreciación, como ya se ha visto al considerar los fundamentos neoplatónicos de praxis y theoria, hizo casi imposible dar valor a la praxis, excepto como preparación para la theoria o como influjo sobre ella. Ciertamente, hay razones filosóficas para oponerse a este prejuicio (que Ellacuría, seguramente, conoció y usó). Sin embargo, también hay importanles razones "espirituales", pues este prejuicio hace imposible que se desencadene en su lotalidad la fuerza del conceplo y de la práctica de "la contemplación en la acción", tanto tomado en su generalidad como en su forma específicamente ignaciana. No es exagerado a firmar que el objetivo de la "filosofía de la realidad histórica" de Ellacuría era vencer este prejuicio, tan dominante en la tradición filosófica. Ni siquiera san Agustín pudo escapar a él, y la solución de Eckhart valoró la participación temporal, pero de manera peligrosamente abstracta, como se verá a continuación.

La discontinuidad crucial de Ellacuria con respecto a Eckhart se puede discutir desde la perspectiva agustiniana ya analizada. Para san Agustín, el modelo griego de praxis y theoria tenía que organizarse alrededor de un centro de gravedad cristológico y tenía que ser coordinado en términos de la primacía del amor. En el pensamiento de Eckhart, esto acaece al centrarse en el nacimiento del Hijo de Dios (en varios modos y lugares) y la calidad de ser fructífero que lo acompaña. Al dar fruto en el mundo, el contemplativo en la acción está actualizando la unión de la generación eterna de la segunda persona dentro de la Trinidad con el nacimiento del Hijo en el alma. Lo que no se desarrolla plenamente (o, peor aún, lo que se ignora) en el esquema de Eckhart es la tercera

Liberación y cautiverio: debates en torno al mérodo de la teologia en América Latina, Enrique Ruiz Maldonado (ed.) México, 1975, 609-635. El pasaje citado está en la p. 626. Para una reconstrucción más cxiensa de la filosofía que Ellacuría cslaba Iratando de desarmollar, y de sus implicaciones para cl método icológico, véasc Burkc, The Ground Beneath the Cross: The Theology of Ignacio Ellacuria, Washinglon (20)(0), capitulos 25; Robert Lassalle-Klcin, "The Critical and Crcative Debt of Ignacio Elacuría to Xavier Zubiri"; Hecctor Samour, "Filosofía y libertad," Ignacio Ellacuria: "Aquella libertad esclarecida", pp. 103-145.

56. Véanse los tres puntos introductorios de la conlemplación, que recalcan las mancras en que Dios está presente como el que hace donaciones, como cl que sostienc lodas las cosas creadas y como el que obra y trabaja para nosotros: Ejercicios espirituales. nos. 234-237 (205s.). 
instancia de la relación de Dios con el mundo a través del Hijo: la encarnación histórica del Hijo en Jesús de Nazaret, la cual continúa históricamente en la Iglesia, a través del poder del Espíritu. Como de esta manera es desligado de sus amarras históricas, "el ser fructífero" que caracteriza al contemplativo en la acción se hace precariamente abstracto. Y esta abstracción es la que permite que el modelo sea privatizado y pueda ser aplicado sin discriminación a casi cualquier acción que no sea abiertamente inmoral. Lo que falta son criterios concrelos o un método para discernir qué formas de trabajo en el mundo se abren a la contemplación en la acción.

El enfoque de Ellacuría también se remonta a la forma trinitaria del ser de Dios y, por consiguiente, de la relación de Dios con el mundo y con los seres humanos en el mundo. Sin embargo, añade a esto el énfasis en la historia, y ya vimos que trata de mostrar y analizar que ese énfasis es el elemento clave de los Ejercicios espirituales de san Ignacio. Ellacuría se cenlra implacablemente en el encuentro "místico" (en el sentido de un "misticismo del aconlecimiento histórico") con el Jesús histórico que los Ejercicios ponen a nuestra disposición. Por lo Ianto, para Ellacuría "el ser fruclífero" depende ante todo de que la persona recapitule en su vida la historia de Jesús de Nazaret. "Es, por tanto, en el seguimiento histórico de la vida histórica de Jesús, donde se va a dar la verdadera contemplación cristiana en la acción":57. Eslo supone una enmienda crítica al ideal de "encontrar a Dios en todas las cosas":

No se trata tanto de encontrar a Dios en todas las cosas. como si Dios estuviese de la misma forma en todas las cosas o estuviese en ellas del mismo modo; evidentemente, no está Dios del mismo modo en el Partenón de Atenas y en Jesús de Nazaret, y no está Dios del mismo modo en la dominación que en la opresión... Se trata de encontrar al verdadero Dios en una forma real. La Escritura nos muestra que son dos cosas distintas el Dios verdadero y el encuentro verdadero con Dios; no basta con el "reconocimiento" de aquél para que se dé éste. Consecuentemente, la contemplación, esto es, el momento de la fe, no será verdadera si la acción en la que se realiza no es la exigida realmente por el seguimiento histórico del Jesús histórico"‘:*.

La esencial inflexión cristológica del modelo de contemplación y acción no se logra con una profundización en el fundamento del alma-Dios en que ocurre la generación etema del Hijo, con la que la encamación en la historia y la respuesta hislórica individual sólo se relacionan a posteriori y extrínsecamente. Más bien, esta inflexión cristológica se deriva de poner en relación la propia historia de una persona con la historia de la vida, la obra y el destino de Jesús. Así, volvemos al punto central de los Ejercicios espirituales, tal como lo interpretó

57. "Lectura", p. 147.

58. Fe y Jusficia, p. 210. Compárese con "Historicidad", pp. 368-37!. 
Ellacuría. Vista de otra manera, desde la perspectiva de Ellacuría, la sabiduría radicalmente encarnatoria de los Ejercicios significa que "es siempre necesaria una presencia humana y una acción histórica para que se haga presente Dios"s". Eso se aplica incluso al hacerse Dios presente al individuo en la oración y $a$ fortiori a la unión de contemplación y acción. El encuentro con Dios no es actualizado ni expresado, primero ni aun principalmente, en imágenes o palabras, ni siquiera en las elevadas palabras del dogma y la teología. Su actualización principal proviene del estar encarnado en una vida realizada históricamente, una vida vivida con espiritu, como le gustaba decir a Ellacuría

Según esto, para Ellacuría, como para Eckhart, la unio mystica se basa en las relaciones trinitarias de Dios con el mundo y supone "la integración ontológica de la persona en la obra divina de la salvación" ésta sólo acaece en la medida en que la persona configura su vida en el seguimiento de Jesús. Esto, a su vez, significa que no cualquier acción puede ofrecer el material dentro del cual acaece tal integración. Más allá de la rectilud moral o de la legalidad eclesial, tal acción debe responder a los criterios del seguimiento de Jesús, que incluye los anteriores, pero va más allá de ellos. De esta manera, Ellacuría recupera la intuición agustiniana de que la acción y la contemplación pueden ser integradas de manera auténtica y fruclífera sólo en la relación con Jesucristo -y lambién en relación con Jesucristo hay que comprender el desarrollo más tardío de la tradición de la importancia del "ser fructifero" para comprender la relación acción y contemplación-. Ellacuría muestra que dar de comer al Jesucristo que continúa encarnándose en los pobres - y cómo hacerlo- es la matriz esencial y activa dentro de la cual la persona es alimentada por Jesucristo en el Espíritu.

Por lo que toca a san Agustín, la sintesis de Ellacuria también ofrece una fuerte dimensión eclesiológica. Ya hernos visto que, desde la perspectiva de san Agustín, la vita mixta se configura según la dimensión específica de la Iglesia como comunidad escatológica, un pueblo que está in statu viae. Esto también es verdad para Ellacuria, pero para él el caminar a través de la historia está inextricablemente unido al compromiso con la historia. "Su praxis [de la lglesia] fundamental consiste en la realización del reino de Dios en la historia, en un hacer que lleve a que el reino de Dios se realice en la historia"w?. Al llevar a

59. “Lcclura”, p. 125.

60. Ihid. Sobre la importancia para el quehacer leológico de actualizar la vida de Jesús en las circunstancias de hoy, vćase Teología política, San Salvador, 1973, pp. 10-15.

61. Micth, op. cit.

62. "La Iglesia de Ios pohres: sacramento histórico de liheración", en Mysterium Liberationis II, p. 134. En su interpretación de los Ejercicios espirituales, Ellacuria lo cxpresó de la siguiente manera: "Los scguidores del Jesús histórico, como pucblo de Dios en el seguimiento histórico, preparan la llegada definiliva del reino de Dios" ("Lcclura". p. 127). 
cabo esta tarea, nunca acabada, la Iglesia realiza su vocación de ser "el pueblo de Dios que prosigue en la historia lo que selló definitivamente Jesús como presencia de Dios entre los hombres" ${ }^{\text {"3. }}$. Esta continuación histórica es precisamente el tipo de "hislorización progresiva" que Ellacuría identificó como el lugar para la "contemplación en la acción". Así pues, ser contemplativo en la acción significa integrarse en este pueblo de Dios y en su tarea interminable de sembrar en la historia "una pequeña semilla que poco a poco puede convertirse en un gran árbol capaz de albergar a todos los hombres" La contemplación en la acción no se puede realizar aisladamente, sino sólo en una comunidad ${ }^{\text {ts. }}$.

Como el advenimiento del reino siempre supone quitar el pecado del mundo, al oponerse a las fuerzas sociales e históricas que deshumanizan a los hombres y las mujeres, este advenimiento se describe mejor en términos de liberación. En cada época, la Iglesia debe "escrutar a londo los signos de los tiempos" para ver la forma específica en la que esia praxis le es obligatoria, y el lugar en el que se debe enfocar dicha praxis. En nuestra época, insiste Ellacuría, esta forma es la lucha por la justicia y el lugar es el lugar de los pobres. La lglesia, por consiguiente, debe no sólo luchar por los pobres, sino que debe - como se insistió en Medellín y Puebla - encontrar su lugar allí, encamarse alli, con ellos. Este "Iomar came" no signilica que la corporización física de la lglesia en sus instituciones y en sus miembros sólo es posible en los lugares geográlicos donde se encuentran los pobres. Pero sí exige que esta encarnación se exlienda a y modifique sustancialmente incluso ( $\mathrm{i}$ cspecialmente!) aquellas instituciones y estructuras eclesiales que no se ubican geográficamente entre los pobres ${ }^{\text {tht }}$.

Tenemos aquí una respuesla a la lendencia moderna de convertir la espiritualidad en cómoda mercancia y venderla a los hombres y mujeres del mundo modemo. Esta sintesis de la contemplación y la acción no puede ser privatizada, según

63. "La Iglesia de los pobres". p. 127.

64. Ihid., pp. 15Is.

65. Explorar las raices de las ideas de Ellacuría sobre la "eclesiologia" de la espiritualidad ignaciana sobrepasa la finalidad de cste cnsayo. Pcro hay que decir que John O'Malley, en su magistral análisis de los primeros jesuitas, sostiene que comprendieron la Iglesia desde lo que fue absolutamente central a su identidad: la misión. Afirma que consideraban la Iglesia como "la viña del Scñor" donde fucron llamados para imilar a los apóstoles y los Jiscípulos de Jesús en el ejercicio de su consueta ministeria. [John W. O'Malley, The First Jesuits, Cambridge, 1993, p. 301]. La Iglesia fue para cllos cl lugar escncial donde sc servia bajo la handera de Crisio, como fueron instruidos por los Ejercicios.

66. Ellacuría se ocupó de manera vigorosa de este tema en sus reflexiones sobre una univcrsidad cristiana. Véasc, por cjemplo, "Diez años despućs, ics posiblc una universidad distinta?" en Escritorios universitarios, Erasmo Ayala (ed.). San Salvador. 1999, pp. 49-92. Véase lambién las reflexiones de Jon Sobrino sobre el "lugar" de la fe cristiana y la tcologia en "Theology in a Suffering World: Theology as Imellectus Amoris," Pluralism and Opression: Theology in World Perspective, Paul F. Kniller (ed.), Lanham, 1991. 158-161. 
Ellacuría, porque requiere que la persona sea parte de un pueblo, el pueblo de Dios, que considera como su tarea el continuar la presencia de Jesús en la historia. Demasiados "escritos modernos sobre espiritualidad", al asumir el modelo de la contemplación en la acción, hacen absiracción de la realidad central del seguimiento de Jesús y del contexto social de la Iglesia. Ellacuría mostró cómo y por qué esto distorsiona fundamentalmente el modelo. Esta crítica no elimina "una espiritualidad en los negocios" (spirituality of bussiness) o "una espiritualidad del trabajo universitario", que haría uso de los formidables y loables recursos ofrecidos por un "misticismo de lo cotidiano". Sin embargo, sí somete estas espiritualidades a los criterios del seguimiento de Jesús, derivados y aplicados dentro de una metodología concreta (la de los Ejercicios espirituales). Además, las hace responsables ante un pueblo que ha hecho suyo el trabajo de hacer real el reino de Dios en la historian?. No es fácil responder a estos dos desafíos; cxige una estricta ascesis espiritual. En efccto, Ellacuría pensaba que esto exigía nada menos que la disposición que san Ignacio formuló en los Ejercicios espirituales, expresada ahora a escala socio-histórica. Se necesitaría algo así como las reglas para un discernimiento de espíritus que está abierto a los recursos intelectuales facilitados por las ciencias sociales, pero lambién contextualizado dentro de un deseo profundo de saber, amar e imitar a Jesús y de hacer que el amor de Dios, hecho concreto en la vida de Jesús, sea tambićn una realidad en nuestra vida. La contemplación en la acción de la justicia no es un baralo barniz espiritual que se pueda aplicar a todas nuestras acciones o a cualquiera de ellas. Pero su capacidad para animar vidas en cl seguimiento de Jesús, que traen vida a las culturas e historias de la muerte, es evidente en la vida de los mártires salvadoreños, que siguieron su lógica, difícil pero crislomórfica, hasla el final.

\section{Conclusión}

Mucho más se podria decir sobre la apropiación de la espiritualidad ignaciana y de su contribución a la integración cristiana de acción y contemplación. No he podido hacer justicia ni al fundamento filosófico sobre el cual Ellacuría consıruyó sus reflexiones sobre la espiritualidad ni a la riqueza de la crislología y la eclesiologia que les dan profundidad y que los hacen tan densiamenle cristianos. Pero, al menos, este escrito muesira cómo el compromiso vivido fundamentalmente por Ellacuría con la espirilualidad ignaciana floreció en una filosofía y una teología que, a su vez, enriqueció esa espiritualidad. He tratado aqui de demostrar la importancia de la espiritualidad ignaciana para la

67. Y sc podría añadir que una "espiritualidad del saccrdocio ministcrial" cstá igualmentc sujela a esios requisitos, algo que no es evidenle siempre hoy día. Para un intento de responder a csios crilcrios, véasc Jon Sobrino, "Hacia una detcrminación de la realidad sacerdolal. El servicio al accreamicnlo salvífico de Dios a los hombres," en El principio misericordia: Bajar de la cruz a los pucblos crucificados. San Salvador, 1992, pp. 161-210. 
producción filosófica y teológica de Ellacuría y la influencia que esto ejerció en su articulación - muy ignaciana- del ideal de la contemplación en la acción. Esa integración preserva los logros hechos por la "democratización" de Eckhart de la unio mysica, pero supera una abstracción peligrosa que la había hecho susceptible de ser privatizada y de convertir la espiritualidad en una mercancía, tentación que permea las modernas sociedades del actual capitalismo.

El análisis que hemos hecho lleva a una última reflexión. El énfasis de Ellacuría en la praxis y en la centralidad para la fe, la práctica y la teología cristiana de la lucha por la justicia ha hecho que algunos lo acusen a él (y a casi todos los otros teólogos de la liberación) de ser marxista, de entregar la sustancia de la fe a una conceplualidad intelectual extranjera. Todo lo dicho, sin embargo, sugiere que Marx entró relativamente tarde en el debate sobre praxis y theoria, debate que ya había sido llevado a cabo durante muchos siglos, aunque en términos diferentes (la relación entre la vita contemplativa y la vita activa). Si Ellacuría retomó este debate fue, en gran parte, porque él lo vivió en la espiritualidad que, en definitiva, definía quién era él, cómo pensaba, cómo vivía y, finalmente, cómo murió. La obra de Ellacuría (junto con la teología de la liberación en su tolalidad) seguirá siendo "un clásico", una fuente "clásicamente" teológica para la teología, precisamente, porque retoma una veta crucial de la Iradición cristiana. Haciendo uso de un instrumental intelectual adecuado, dondequiera que se encuentre, su obra hace que esas velas de la tradición sean refrescantemente nuevas y vivificadoras para la Iglesia de hoy, siempre que ésta luche por ser fiel a su naturaleza y a su misión.

Traducción de Geraldine Ameriks 